\section{CLINICAL LECTURE}

ON

L O C O M O T O R A T A X I A.

BY DAVID J. BRAKENRIDGE, M.D., F.R.C.P.E.,

Physician to the Royal Infirmary; Lecturer on Clinical Medicine; Edinburgh.

Gentlemen,-I take as the subject of my lecture to-day, sclerosis of the posterior columns of the spinal cord, or tabes dorsalis, or progressive locomotor ataxia, as it has been variously termed. I will illustrate the disease by three cases, in which three different portions of the cord were affected. In the first case, the phenomena resulting from the sclerosis were manifested in the upper extremities chiefly; in the second, in the trunk of the body; and in the third, in the lower extremities.

CASE I. Locomotor Ataxia Affecting the Upper Portion of the Spinal Cord and the Upper Extremities Chiefly.-Joseph Ritchie, aged 48, had, for fourteen years previous to 1870 , played a wind-instrument requiring skilful fingering, in the band of the 78 th regiment. From 1872 till a few months before his admission on September 27 th, 1877 , he had worked in Messrs. Pullar's dye-works in Perth, where his hands were immersed in the fluids a considerable part of each day. His habits had been very irregular, including one good drinking bout each year, lasting a month or six weeks.

His illness began about eight months before admission, with severe, sudden, transient, stabbing pains in the extremities, followed by numbness and anæsthesia in the fingers, and a loss of command over the movements of the fingers, so that his tools fell out of his hands; when he was in the band of the Perth Militia, in June and July I877 (three months before admission), he found his execution failing him; he could not strike the notes with his wonted speed and precision.

November $3 \mathrm{rd}, \mathbf{1 8 7 7 . ~ H i s ~ s t a t e ~ o n ~ e x a m i n a t i o n ~ w a s ~ a s ~ f o l l o w s . ~}$ $\mathrm{He}$ had still occasional attacks of the shooting pains. Sensibility to touch and pain were both decidedly diminished on the extensor aspects of both arms all the way up; also, though to a less degree, on the flexor aspects. On the back of each arm there were two small areas, about one inch in circumference, one situated near the elbow, the other about the middle of the upper arm. In these, sensibility to painful impressions was almost annulled, for the needle might be passed through the mass of muscles, etc., right down to the bone, and pressed against it, without any sensation whatever being experienced. Sometimes the patient felt when the needle was passed through the periosteum. The needle might be left sticking deep in the muscles without exciting any feeling whatever. Once, under these circumstances, the patient, who was unaware of the presence of the needle, at distinct intervals of about half a minute cried out that he had been momentarily touched with something hot at the spot where the needle had been all along sticking. At some points immediately contiguous to these almost absolutely anrsthetic areas, the cutaneous sensibility was perfectly normal. Touch and sudden pressure were felt in some areas better than painful impressions.

A curious fact was roted in this case (which has been observed in all the subsequent cases I have seen), viz., that, after repeatedly pricking or otherwise exciting some of the anasthetic areas, the sensibility was so far restored that a very slight pressure could be felt. In other areas, very frequent piercing of the tissues and other excitations failed to have the slightest restorative effect.

Sensation was delayed at some points, being felt at a distinct interval of two or three seconds after the application of the needle.

In the lower extremities (which were also affected later and to a less extent in this case), this curious fact was observed, that, if the skin were suddenly punctured with a sharp-pointed instrument, the patient at once exclaimed that he was touched, and then, after a short but distinct interval, cried out "That's hot!" and pulled up his leg with a sudden jerk. He stated that he felt, at different times, first the touch and then the heat. In many of the anæsthetic areas, he mistook heat for cold, and vice vers $\hat{\text {. }}$.

When asked, with his eyes shut, to bring the points of his index fingers together, he first looked at his fingers carefully, then shut his eyes, and rapidly brought his fingers to within an inch or two of each other; then he hesitated, and was quite at a loss how to proceed; because, as he stated, although conscious that his hands were near one another, he was quite uncertain as to their relative position. If he tried to touch a given point with his eyes open, he looked at it, took aim with his finger, advanced it rapidly and tolerably steadily till near it ; then the movement became very unsteady, and was finished slowly and with evident effort to control the irregular action of the muscles. In writing, he pressed hard upon the paper, as if to increase the intensity of the sensory impressions. He could thus write legibly, but badly, with the eyes open, and fixed anxiously on his fingers. When his eyes were shut, he made only a few widely disconnected strokes. The power of distinguishing weights was impaired in both arms.

The pupils were contracted. The diameter of the right was two lines; of the left, one line. There was no colour-blindness. The fundus was healthy in both eyes. Micturition was often painful and feeble.

CASE II. Locomotor Ataxia Affecting Principally the Portion of the Cord between the Cervical and Lumbar Enlargements, and consequently the Trunk Chiefly.-The case is an interesting one, as there was no locomotor ataxia present in either arms or legs. The possibility of the occurrence of such a case should be borne in mind.

Frederick B., a lamplighter, aged 32 , had fallen off the top of a railway-carriage six years before his admission in October 1878; but, although stunned and severely bruised, he recovered, and was well until a year ago, when, during an attack of bronchitis, he first complained of pain in the back. It left him after a time, but returned a few months later, after an attack of pleurisy, and his condition at the beginning of November last may be briefly described as follows. $\mathrm{He}$ was well nourished. He complained of a constant dull aching pain over the spine, which was aggravated by movement, and then became sharp and stinging in character. There was no paralysis, spasm, or atrophy of any muscle. The pain in the spine was not increased by hot or cold sponges passed over the painful parts; there was no paralysis of the sphincters of the bladder or rectum. The disturbances were entirely limited to the sensory nerves and nerve-tracts. There was marked hyperæsthesia from the second dorsal vertebra downwards; the slightest superficial touch causing severe pain. This was most intense over the eighth, ninth, tenth, and eleventh dorsal vertebræ. Curiously, over this very area, where the hyperæsthesia was greatest, the power to distinguish the heat of a very hot sponge was completely lost. The lateral aspects of the back of the body, on each side of the spine, were similarly affected.

Anæsthetic areas-insensible to impressions of touch and pain-were discovered and carefully mapped out in the following regions; one about the insertion of the deltoid on both arms; on the right arm, one a little below this, and one on the posterior surface of the forearm; one over the right ilium, passing on to the trochanter; and one similarly situated on the opposite side. Electro-sensibility was diminished over the triceps and deltoid on the left arm, and over the anæsthetic area on the right thigh:

It was thought advisable to have the circumference of each area mapped out with nitrate of silver. This was done on the right side, and partly on the left. Next day, it was found that the caustic had been applied too strongly, and had blistered the skin along the line of its application. This curious and interesting fact was also further noted, that, in some of the anæsthetic areas so treated, sensibility was completely restored; in the others it was partially so; while, on that day, the areas on the left side, not so treated, remained quite as anæsthetic as before. On the second day after the application of the caustic, sensibility was found to have been recovered to a considerable extent in those areas which had not been mapped out with nitrate of silver. This interesting fact corresponds to the effect of repeated pricking in the other cases.

CASE III. Lower Portion of the Cord and Lower Extremities Chiefly' Affected.-John S., aged 38, labourer, married, had, at twenty years of age, contracted syphilis, and, at twenty-three years of age, was ill for a month from a cart having passed over the middle of his body. He had been a hard drinker, and in early life was addicted to venereal excesses. The family history was unimportant.

Seven months before admission on January 4 th, 1879 , he began to complain of weakness in the legs; also of instantaneous, sharp, darting pains, shooting from the knees to the toes; slighter pains of similar character in both lumbar regions; also formication, numbness, etc., in the lower limbs. Some weeks later, he noticed a tendency to fall forward into the basin while washing his face.

$\mathrm{He}$ is fairly well nourished. He has no feeling of constriction round the body or limbs. Besides the pains already referred to, he has occasional numbness and tingling of the lower limbs. Sensibility to touch is somewhat impaired in both lower limbs; but over the dorsum of both feet, and over the middle of the tibia, he cannot distinguish between the prick of a needle, and pressure with the finger firmly applied. With his eyes closed, he can describe accurately how 
his legs are placed or flexed. There is an absence, in his case, of that feeling of something soft, like felt or wool, under the feet, which is so frequent in and characteristic of this disease. Sensibility to impressions of heat and cold is normal, except over the lower two-thirds of the posterior surfaces of both legs, where both hot and cold sponges are felt warm. Tickling the soles of the feet is felt, but occasions no reflex movement. Tickling the dorsum of the foot is felt as scratching.

On pricking the patient deeply with a needle on both lower limbs, a considerable interval elapses between his feeling the touch and the sensation of pain. Over the tibia and the upper surface of the great toe, the interval is sometimes several seconds. At the lower part of the right tibia on the inner side, there are two small absolutely anæsthetic areas, a quarter of an inch and half an inch in diameter respectively. On the back of the trunk, the interval between the perception of touch and pain is marked, and there are some small anæsthetic areas in the lower lumbar and upper gluteal regions. The patellar tendonreflex is entirely absent in the right lower limb; almost so in the left. Standing with the feet close together, and the eyes shut, he first sways from side to side, and then falls. With his eyes open, he can stand, but he closely watches his feet; and the whole of the balancing muscles of the limbs are seen to be in a state of rapid clonic contraction, evidently in order to steady him. In walking, he separates his feet somewhat, and lifts the foot higher, and throws it more outwards than normal. When the foot is brought to the ground, the heel comes down first with some force, and afterwards the foot with a flap. On attempting to describe an arc of a circle in the air with his leg, he can only do so in a jerking zig-zag way. Although his legs are small, there is no muscular atrophy. His muscular power in both legs is good, and he can overcome powerful attempts made to prevent his extending or flexing his lower limbs. Electro-contractility is normal. His eyesight is much impaired. Both pupils are dilated, especially the right; but contract on looking at a near object, and with strong light. Ophthalmoscopic examination reveals grey degeneration of the optic nerve in both eyes, most marked in the right.

$\mathrm{He}$ has great difficulty sometimes in micturating. The urine is strongly alkaline, and contains abundant triple phosphates. His intelligence and memory are somewhat impaired. He often has cramps in the upper and lower extremities.

This disease attacks males much more frequently than females. It occurs usually between thirty and fifty years of age. Its occurrence has been attributed to a good many causes, among which may be mentioned: I. A neuropathic tendency, which is certainly often present; 2. Certain occupations entailing great exposure or bodily exertion; especially such as necessitate unusual movements of co-ordination, as in the case of railway-guards or musicians; 3. Mental fatigue and over anxiety; 4. Acute and chronic diseases; 5. Accidents; 6. Sexual excesses and onanism; 7. Syphilis, and many others.

In all the cases read, we have, at first, symptoms of an initial period, indicating slight commencing sclerosis and congestion, c.g.: I. Sharp electric-like neuralgiform pains; 2. Disturbances of vision, such as diplopia, amblyopia, etc.; 3. Various forms of parresthesia, such as numbness, formication, sense of something soft under the feet, girdlefeeling of constriction round the body; 4. Sensation of motor insecurity, fatigue on slight exertion, tendency to fall in the dark or with the eyes shut ; 5. Disturbances of the bladder and sexual organs.

The cases given illustrate very well the most important characteristics of the fully formed disease. We may sum these up as follows: I. Alterations in the cutaneous and deep sensibility, and conduction of centripetal impressions; 2. Absence of any true motor paralysis; 3 . Absence of any true muscular atrophy; 4 . Loss of ability to co-ordinate the muscles; 5. Ocular affections.

In these cases, we have seen that the alterations of cutaneous sensibility may affect: I. Sensibility to tactile impressions, as estimated by touching, and by testing the power to distinguish accurately the distance between the points of the rsthesiometer; 2. The ability to feel pain, estimated by piercing the skin with a sharp-pointed instrument, etc.; 3. The power to distinguish between different degrees of temperature; 4 . The sensibility to electrical impressions.

All of these may be modified, as we have seen, in the following ways: I. They may be increased or diminished-usually they are diminished; 2. The transmission of impressions may be delayed; 3 . The power to localise the impressions accurately may be lost; 4. One kind of impression may give rise to a sensation of a different kind, as when a sensation of heat resulted from piercing the skin with a needle.

The muscular sensibility may be affected in similar ways; but of course it is more difficult to test the exact conditions in the deeper tissues. In Ritchie's case, wherever the skin was sufficiently insensible to permit of a needle being passed through it unperceived, it could be run down through the muscles to the bone without being felt.

The power of distinguishing accurately between different weights is usually, as in these cases, more or less impaired.

The action of the reflex tendons is, as a rule, greatly diminished or altogether abolished, so that, e.g., a smart blow on the ligamentum patellæ fails to elicit any resulting muscular contraction of the quadriceps extensor.

The errors in the transmission of the deeper centripetal impressionsnot necessarily revealed to consciousness-must be interpreted by and regarded as similar to, those which can be accurately studied as sensory disturbances.

It is very noticeable in all these cases, that spots quite insensible to painful impressions-so anæsthetic in Ritchie's case, that a needle driven right down to the bone through several inches of muscle was not felt-were distant not more than two or three lines from spots where the slightest superficial prick was acutely felt. If the two points of the æsthesiometer strike two such different areas, of course only one will be felt. Hence it is not, strictly speaking, an accurate test of the power of distinguishing distance between the points.

Sometimes, repeated or prolonged excitation of one of these abnormally insensible areas-by pricking, as in Ritchie's ır Smith's cases, or, as in the case of Birnie, by caustic - had the effect of restoring their sensibility for a time; overcoming, in some manner not yet very clear to me, the obstacle presented to the transmission of impressions in nerve-tubes not yet completely interrupted. This fact explains in some measure that delay in the transmission of impressions which is met with to a very marked degree in some cases; as for example, in the case recorded by Dr. Hammond, in which, "when the feet were put into hot water, the sensation was not felt for almost three minutes" (Diseases of the Nervous System, p. 586). In such a case, the continued excitation, acting as repeated stimulations, may, by acquiring a cumulative force, overcome the resistance in the obstructed nerve-path, and sensation ultimately result. In a similar manner, in one area in Ritchie's arm, the needle left sticking deep in the tissues, gave rise only to a transient sensation felt every half-minute; the influence passing as it were slowly, guttatim, along the imperfect conductor.

The case is altogether different when a single, momentary, or very brief impression is not felt until some time after the exciting body has been removed. Here a real delay in transmission seems to occur. In Smith's case, when a sharp-pointed instrument was applied to the skin, the tactile sensation was felt at once, and the painful impression a second or two later. In Ritchie's case, there was this very curious modification of the result, that, while the patient exclaimed at once that he was touched, after a short but distinct interval he cried out "That's hot!" and pulled up his legs. This point was most carefully tested by repeated experiments. In both cases, it would appear that the tactile and painful impressions travelled at different rates of rapidity along their respective nerve-paths, the painful impression being abnormally delayed.

The conversion of one kind of impression into a quite different resulting sensation, was well exemplified in Ritchie's case; the painful impression giving rise, not to a sensation of pain, but to one of heat. The same curious fact was also observed in the case of a man, Silver, in the same ward.

The erroneous localisation of impressions was present to a certain extent in Ritchie's case, and is often well seen in cases of locomotor ataxia; a tactile impression made at one point being referred to a quite different locality, perhaps to the opposite limb.

The ocular disorders vary much in different cases, and bear no proportionate relation to the severity or extent of the disease. In Ritchie's case, in which the disease was very extensive, all that was observed was, that contraction of the pupils, not influenced by light, and only moderately removed by atropia, which is usually met with from implication of the sympathetic nerves when the so-called "cilio-spinal centre" in the spinal cord, opposite the lower cervical and upper dorsal vertebræ, is implicated in the sclerosis; otherwise his eyes were healthy. In John Smith's case, where only the lower extremities are affected, diplopia, and also commencing amaurosis from grey atrophy of the optic nerve, are present.

In some cases, the power to distinguish certain colours is lost.

The first and third cases have furnished you with a good idea of the forms of inco-ordination met with in this disease. The mechanism of that inco-ordination I will discuss further on.

What are the anatomical lesions in this disease? You will remember that, in early life, the posterior columns of the spinal cord are divided by a deep fissure into two unequal parts. The inner portion is the slender column of Burdach or the column of Goll; the outer and larger, bounded internally by the column of Goll, and externally by the 
posterior cornua of grey matter, is the external band of the posterior column; it is also called the posterior root-zone. Sclerosis of the inner division of the posterior column - the column of Goll-does not appear to give rise to the characteristic phenomena of this disease; while it is always present when the posterior root-zones are affected.

Dr. J. Lockhart Clarke has further demonstrated that to the posterior root-zones are principally attached the posterior or sensory roots of the spinal nerves, not to the lateral columns, as was once believed. Usually the posterior cornua of grey matter are to some extent implicated in the sclerosis. The posterior roots of the spinal nerves are almost always found to be atrophied.

Similar alterations from degeneration are found in parts within the cranium, which are closely related to the posterior columns of the cord; as, for example, in the lower cerebral peduncles, the restiform bodies, and the optic thalami. The optic nerve is often affected, and the grey degeneration in it may often be detected very early in the disease by means of the ophthalmoscope.

Chronic neuritis-the result of implication of the cilio-spinal centre, upon which also depends the contraction of the pupil in these casesis also frequently met with in this as in other spinal diseases.

You must not expect to find the disease always strictly limited to the posterior root-zones and the adjacent grey matter of the spinal cord. Other regions are often invaded in the progress of the disease, and you will then have contractions, paralysis, atrophy, or disease of joints superadded, according to the region involved.

[To be continued.]

\section{PNEUMONIA, WITH COPIOUS HÆMOPTYSIS, TREATED BY ERGOT: SPEEDY RECOVERY.}

By C. HANDFIELD JONES, M.B.Cantab., F.R.S., Physician to St. Mary's Hospital.

J. D., AGED 21, messenger, was admitted May 19th, 1873. His health had been generally good. His family were healthy; there was no phthisis in his brothers and sisters. He was taken ill on the 16 th, about noon, with pains in the chest and back; he had no shivering. He had some dry cough before he was attacked, but did not spit up anything. He had not lost flesh. There was a little trace of herpes at the left corner of the mouth. On the I6th, he brought up by coughing much blood, and had continued to do so till noon; he estimated the quantity at a pint. The cheeks were flushed. Temperature I04 $^{\circ}$; pulse 96 , pausing completely now and then; respiration 47 . There was good resonance in both fronts. The breath-sound was harsh and rather weak under the left clavicle; in the third space it was normal. Below the right clavicle the breathing was also weak and harsh, and attended with prolonged expiration. Good resonance and breathing were heard in all the right back and in the upper third of the left ; in the lower half, or rather more to the left, there were marked dulness, bronchial breathing, and bronchophony. He had had pain in the left side; not much now. He lay down flat. He slept very badly last night. He was ordered to have a turpentine fomentation applied to the whole back, and to take a drachm of fluid extract of ergot and an ounce of mistura ammonia acetatis four times a day, and to have simple diet, with milk. On the 2oth, he had had a better night; the bronchial breathing and crepitations were heard higher up in the left back than on the igth. The sputa were mucous, mixed with red blood. Beef-tea and two eggs were added to the diet. $\mathrm{He}$ was ordered to have five grains of mercury and colocynth pill at bed-time. On the 21st, the sputa were still much bloodstained. On the 22nd, the left lower back was decidedly more resonant bronchial breathing had ceased; some vesicular respiration was heard. The sputa were less, almost quite free from blood; his appetite was better. 24th. There were scarcely any sputa; what there was was only clear mucus. He was eating boiled sole. There was fairly good breathing in the lower left back. The ergot was omitted, and he was ordered to take twenty minims of liquor ferri muriatis and fifteen minims of spirit of chloric ether, in an ounce of water, three times a day. On the 29th, breathing under both clavicles was somewhat weak and harsh; he had no expectoration; and he was walking about apparently well.

$$
\begin{aligned}
& \text { Date. Temp. Resp. Pulse. }
\end{aligned}
$$

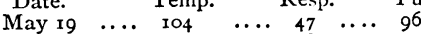

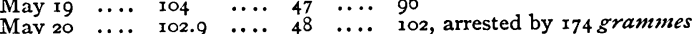

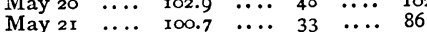

$$
\begin{aligned}
& \begin{array}{rrrrrrr}
\text { May } 21 & \ldots . & 100.7 & \ldots . & 33 & \ldots . & 86 \\
\text { May } 22 & \ldots . . & 98.6 & \ldots . & 44 & \ldots & 78 \text {, arrested by } 174 \text { grammes. }
\end{array}
\end{aligned}
$$

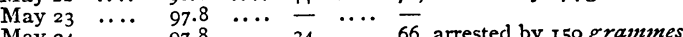

$$
\begin{aligned}
& \text { May } 24 \text {.... }
\end{aligned}
$$

The duration of the disease, from commencement to defervescence, was six days; to nearly complete resorption of exudation, eight days.
The hæmoptysis was unusually profuse, and naturally suggested the remedy.

The foregoing history was recalled to my recollection by perusing the case recorded in the JouRNAL of November 15 th (page 772), of "rapid cure" of pleuropneumonia by ergot. In both, the action of ergot seems to have been beneficial ; but I demur to the assumption that it effected a cure. Nothing seems to me more certain than that ordinary pneumonia (pneumonie franche), at any rate as we see it now-a-days in London, runs a determinate course ; the inflammatory process terminating, by more or less rapid defervescence, about the sixth or seventh day from the initial rigor; while the exudation undergoes resorption sooner or later, according to the energy of the vital powers. If this be so, it is clear that we must be very careful not to deceive ourselves by attributing to our remedies what is really due to the natural course of the disease. Further, we must take good heed not to employ any means which injuriously affect the patient's strength, and especially we must be cautious of doing anything which may enfeeble the heart. Jurgensen emphasises this caution strongly (German Clinical Lectures, New Sydenham Society, 1876), and I quite agree with him, though I do not think his heroic measures are often requisite. Though we cannot cure the disease, we may, however, materially mitigate its severity, and sometimes no doubt save life. Ergot and liquor ferri perchloridi may check and control the inflammation; opium may allay pain, and calm and steady the nervous system; bark and ammonia, with wine, may give tone to the failing heart, especially in the collapse of the crisis ; effervescing salines, or brandy and soda-water, with or without a dose or two of calomel, may quiet gastric irritation, and enable the patient to take food better; quinine in large doses, or the cold bath, may serve our need in dangerous hyperpyrexia. There is plenty of scope for beneficent and well-directed action; but, as we have only to gain time to win, no risk should be incurred with the idea of cutting short the disease. Such, at least, is my experience in London. It would be very interesting to know whether that of other practitioners elsewhere is different. Hjaltelin's in Iceland certainly seems to have been so ; but Dr. Hughes Bennett's at Edinburgh, and Jurgensen's at Kiel, is essentially similar. With regard to ergot, I may mention that, though I have tried it in various inflammatory affections, notably in bronchitis, it has on the whole disappointed my expectations. Theoretically, it ought to be a great remedy for inflammation; but practically, it has not often accomplished much.

\section{STATISTICAL REPORT OF ALL UPERATIONS PER- FORMED ON HEALTHY JOINTS}

IN HOSPITAL PRACTICE, BY MR. LISTER, FROM SEPTEMBER I87I TO THE PRESENT TIME, TOGETHER WITH SUCH ACCIDENTAL WOUNDS OF JOINTS AS OCCURRED DURING THE SAME PERIOD. By W. WATSON CHEYN E, F.R.C.S.,
Surgical Registrar, King's College Hospital.

A DESIRE has been frequently expressed that a statistical account of some of the results of the antiseptic method of treatment in Mr. Lister's own hands should be published; and with the view of satisfying this reasonable wish the following cases are brought forward.

In comparing the results of one method of treatment with those of another, it is not sufficient to state these results merely numerically; some idea of the nature of the individual cases must be given; but to publish all those which have occurred in Mr. Lister's practice since the commencement of antiseptic treatment in sufficient detail to convey a correct impression of their nature would be a very laborious work; and further, such a paper would contain many cases of little interest, which, however, could not be omitted without laying oneself open to the charge of withholding part of the results. I have, therefore, with Mr. Lister's permission, selected a series of cases which must be looked on as crucial tests of the treatment, viz., those where healthy joints have been opened by incision or through accident and kept open for some days.

This paper will accordingly contain an account of all such cases which have occurred in Mr. Lister's hospital practice since September I871 up to the present time. I begin at 187 I, partly because the note-books conveniently accessible to me commence at that date, and partly because the time, the spray and gauze being substituted during that year for syringes and lac-plaster.*

* See the British Medical Journal for January $\mathbf{r}_{4}$ th, 1871 , where the firs mention is made of the use of the gauze and spray, and where a very instructive case mef in is is ocated forwards is given. (Compare with this case No. Io.) 